\title{
Genetic relationships in the Sitopsis section of Triticum and the origin of the $B$ genome of polyploid wheats
}

\author{
Nasser Bahrman, \\ Michel Zivy and \\ Hervé Thiellement*
}

\author{
Laboratoire de Génétique des Systèmes Végétaux, \\ C.N.R.S.-I.N.R.A.-U.P.S. La Ferme du Moulon, \\ 91190 Gif-sur-Yvette, France.
}

The proteins extracted from etiolated seedlings of 10 accessions, representatives of the species of the Sitopsis section of Triticum were analyzed by two-dimensional (2D) gel electrophoresis. The 2D patterns were compared and similarity indices were computed between all accessions. From the similarity matrix a dendrogram was deduced, that gave interesting information concerning the genetic relationships between the species of the Sitopsis section. The $2 D$ pattern obtained from the Chinese Spring variety of Triticum aestivum was then included in the analysis. From the dendrogram obtained and also from the number of species-specific proteins shared between Chinese Spring and each of the Sitopsis species, it is proposed that the $B$ genome donor of the cultivated wheats originated from a species closer to the $T$. speltoides $-T$. aucheri group than to any other diploid Sitopsis species.

\section{INTRODUCTION}

For more than half a century numerous experiments have been undertaken concerning the phylogeny of the polyploid cultivated wheats, and recently Kerby and Kuspira (1987) published an extensive review on the subject. However the origin of the cytoplasm and of the B genome of Triticum turgidum and T. aestivum is still a subject of active controversy. We recently took into consideration the variability of 3 cytoplasmically encoded proteins in the genus Triticum (Bahrman et al., 1988). According to these experiments only $T$. speltoides and $T$. aucheri, both from the Sitopsis section, have the same cytoplasmic type as $T$. turgidum, $T$. timopheevi and T. aestivum. It was thus suggested that among the present diploid Triticum species, those two were the closest to the ancient form involved as the female parent of the original $\mathrm{B} \times \mathrm{A}$ cross.

To test this hypothesis further, we performed two-dimensional (2D) gel electrophoresis of seedling proteins on various representatives of the Sitopsis section and compared their whole 2D patterns to each other and to the 2D pattern obtained from the $T$. aestivum variety Chinese Spring.

The comparison of $2 \mathrm{D}$ patterns can indeed be a valuable tool for such investigations since several

\footnotetext{
* Author for reprint requests.
}

hundreds of gene products can be revealed at a time in a single gel and furnish, at this global level, interesting genetic information (Klose, 1982; Zivy et al., 1983, 1984; Thiellement et al., 1987). If two genotypes share identical structural genes they will give rise to gene products located in the same position on 2D gels. One must keep in mind however that, as in conventional unidimensional electrophoresis of enzymatic proteins, not all the alleles will appear at different locations on the gel since only a fraction of the genetic variation will change the charge or the apparent molecular mass of the synthesized polypeptide. Thus, the genetic similarity between two genotypes is systematically over-estimated. Nevertheless this technique allows one to define similarity indices between 2D patterns (Thiellement and Colas des Francs, 1986) and thus to appreciate the genetic proximity between two genotypes, at the level of the expressed portion of the genome.

\section{MATERIAL AND METHODS}

\section{Plant material}

The wild diploid species $T$. sharonense, $T$. searsii, $T$. longissinum and T. bicorne were each represented by two accessions, one, designated 1, obtained from Professor E. R. Sears (University of Missouri, Columbia, U.S.A.) and the second, designated 2, 
from Dr J. Jahier (I.N.R.A. Le Rheu, France). A $T$. speltoides accession was obtained from E. R. Sears and a $T$. aucheri accession from J. Jahier. The common wheat variety Chinese Spring (CS) was obtained from J. Jahier.

Several seeds of each accession were allowed to germinate in the dark in a growth chamber at a constant $20^{\circ} \mathrm{C}$. On the seventh day, the aerial part of the seedlings was cut off and immediately plunged into liquid nitrogen where they were stored until extraction.

\section{Protein extraction and electrophoresis}

Each extract was made of two to four diploid individuals. One accession was represented by at least three well-defined gels obtained from different extracts. The proteins were extracted according to the procedure of Zivy (Damerval et al., 1986) and the electrophoresis performed in $1 \times 200 \times 240 \mathrm{~mm}$ slab gels as described in Bahrman and Thiellement (1987). An example of the gels obtained is shown in fig. 1(a).

\section{Gel comparison}

For each accession a synthetic map was drawn from the three gels in which all the well defined spots found in that accession were retained. Then, a master map was constructed from the 11 such maps (10 Sitopsis accessions and CS). On this master map (fig. 1(b)) are found all the spots taken into account in this analysis. Each spot was considered and we noted its absence or its presence in each of the eleven accessions. Quantitative differences were not considered. Thus, the data is in the form of lines with the spot number followed by a succession of 0 and 1 corresponding to the absence or presence of that spot in the different accessions (the different columns). From this large array we computed similarity indices for each pair of genotypes. In order to have a common reference for all comparisons, all the spots of the master were taken into account for the computation of each similarity index, which was the number of spots commonly absent or commonly present divided by the total number of spots of the analysis. In a first step only the ten diploid Sitopsis accessions and the 1187 spots found among them were considered. In a second step the hexaploid wheat Chinese Spring was included in the analysis and the 1231 spots of the master taken into account. Similarity matrices and dendrograms were computed using the Genstat V statistical software from Rothamsted Experimental Station (1984).

\section{Statistical methods}

The similarity indices were compared using $\chi^{2}$ tests applied to $2 \times 2$ contingency tables for two different pairs. For each pair we took into account the number of spots commonly absent or present and the number of non-common spots. Only the tests concerning the similarity indices between CS and the different Sitopsis accessions are indicated in table 3. The robustness of the dendrograms was assessed as described below in the Results and Discussion sections.

\section{RESULTS}

The number of spots retained in each diploid accession varied from 641 in bicorne 1 to 698 in sharonense 1 whereas the number of Chinese Spring spots was 750 . There were 1187 spots in the Sitopsis accessions and the total number of spots of the master map (fig. 1(b)), i.e., found in the eleven accessions, was 1231 .

\section{Comparison of the $2 D$ patterns in the Sitopsis section}

Of the 1187 spots found in Sitopsis accessions, 348 were present in every accession: $70 \cdot 7$ per cent of the spots were variable, i.e., absent in a least one accession. However, the number of spots found specific to one species (i.e., present in two accessions of the same species but absent in all others) was relatively small: 18 in T. bicorne, 6 in $T$. longissimum, 8 in $T$. searsii, and 8 in $T$. sharonense. Considering $T$. speltoides and $T$. aucheri as members of a same species (see discussion below), its number of specific spots was 31 .

A similarity matrix was computed from the 10 by 1187 array of data (table 1). Similarity indices between accessions varied from 68.8 (sharonense 2 -speltoides) to 84.9 (aucheri-speltoides). Similarity indices between species were smaller than within species. However a large variation was found among the latter: from 78.1 in $T$. searsii to 84.9 in $T$. speltoides-aucheri.

In the dendrogram (fig. 2) computed from this matrix, the criterion used for merging dendrogram classes was the similarity between class centroids. All accessions were merged with a member of the same species before being merged with another species. $T$. searsii accessions (the species with the smallest index of within species similarity) were merged to each other at a similarity level slightly lower than the first merger between species ( $T$. longissimum with $T$. sharonense). Then, T. bicorne 


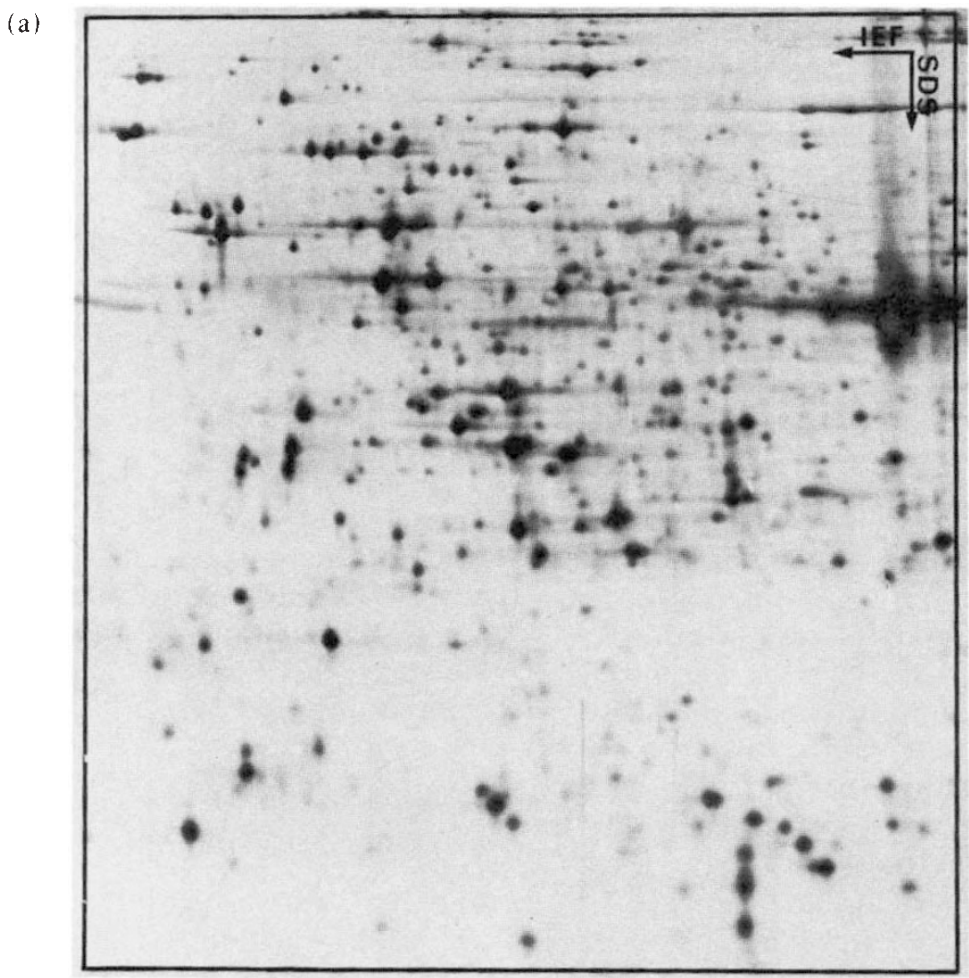

(b)

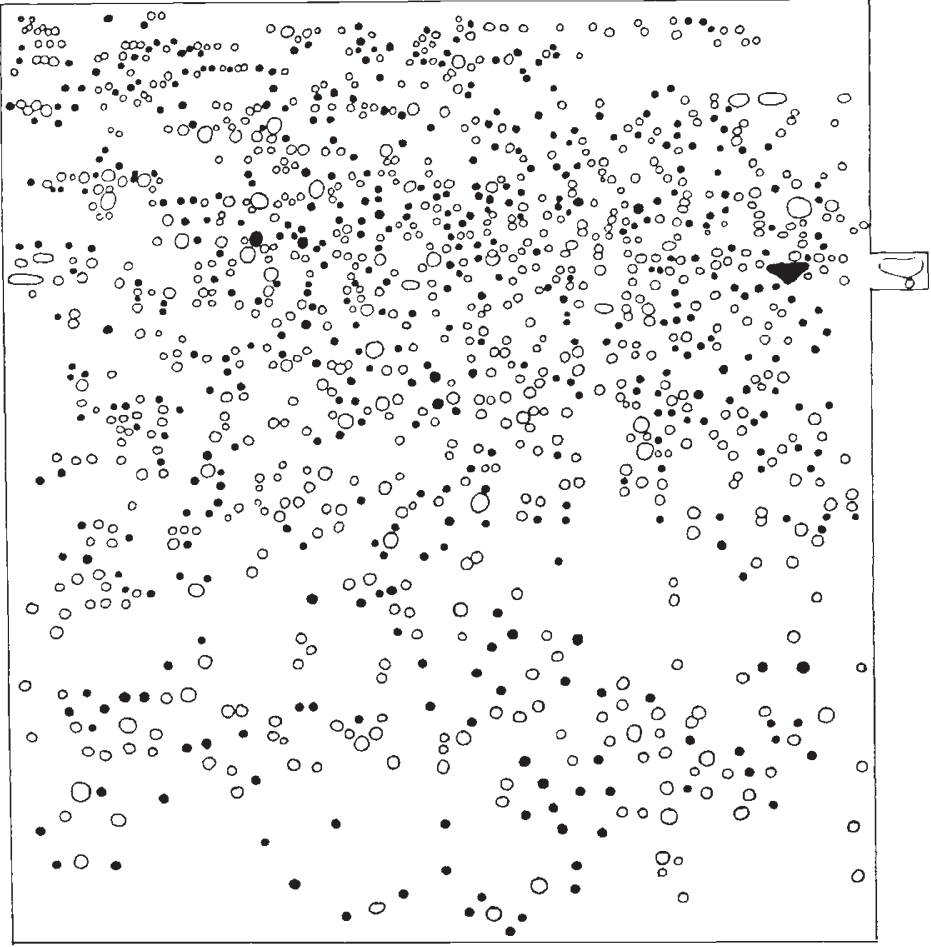

Figure 1 (a) An example of the 2D gel obtained, from the sharonense 1 accession. The portion of the gel analysed is inside the black lines. (b) The master map on which is drawn the 1231 spots found in CS and in the ten Sitopsis accessions. The spots in black are not found in CS. 
Table 1 Similarity matrix between the Sitopsis accessions

\begin{tabular}{|c|c|c|c|c|c|c|c|c|c|}
\hline aucheri & $84 \cdot 9^{*}$ & & & & & & & & \\
\hline bicorne 1 & $73 \cdot 3$ & $72 \cdot 4$ & & & & & & & \\
\hline bicorne 2 & $72 \cdot 1$ & $71 \cdot 7$ & $82 \cdot 6^{*}$ & & & & & & \\
\hline longissimum 1 & $71 \cdot 9$ & $74 \cdot 2$ & $75 \cdot 1$ & $74 \cdot 1$ & & & & & \\
\hline longissimum 2 & $71 \cdot 8$ & $72 \cdot 5$ & $75 \cdot 9$ & $75 \cdot 1$ & $84 \cdot 2^{*}$ & & & & \\
\hline searsii 1 & $72 \cdot 7$ & $72 \cdot 6$ & $73 \cdot 5$ & $75 \cdot 0$ & $74 \cdot 0$ & $74 \cdot 8$ & & & \\
\hline searsii 2 & $69 \cdot 2$ & $70 \cdot 3$ & $72 \cdot 9$ & $77 \cdot 9$ & $72 \cdot 1$ & $72 \cdot 9$ & $78 \cdot 1^{*}$ & & \\
\hline sharonense 1 & $70 \cdot 0$ & $70 \cdot 8$ & $73 \cdot 0$ & $74 \cdot 5$ & $75 \cdot 1$ & $79 \cdot 5$ & $76 \cdot 7$ & $72 \cdot 2$ & \\
\hline \multirow[t]{2}{*}{ sharonense 2} & $68 \cdot 8$ & $70 \cdot 4$ & $72 \cdot 5$ & $73 \cdot 0$ & $76 \cdot 7$ & $82 \cdot 7$ & $77 \cdot 3$ & $72 \cdot 9$ & $82 \cdot 9^{*}$ \\
\hline & spelt & auch & bic 1 & bic 2 & lon 1 & lon 2 & sea 1 & sea 2 & sha 1 \\
\hline
\end{tabular}

* Similarity indices between accessions of the same species.

and $T$. searsii were grouped. This group and the $T$. sharonense- $T$. longissimum one were closer to each other than to the speltoides-aucheri group.

The robustness of this classification was tested by different means. From the same similarity matrix, dendrograms were computed using other criteria. When two classes were compared, instead of looking at similarities between their centroids, similarities between their closest, or between their furthest elements were used. Another test was to compute the similarity matrix from less spots; the 1187 lines-array was randomly divided in two equal parts, and the classification was done on them. This operation was repeated twice. In the two dendrograms computed from the 1187 spots but with different criteria and in the four dendrograms computed from different samples of spots (criterion: class centroids) the main structure of the dendrogram of fig. 2 was conserved: (1) except for the accessions of $T$. searsii, the two accessions of a same species were always merged first; (2) T. speltoides and T. aucheri were closely related and far from all the other accessions; (3) $T$. longissimum and $T$. sharonense form a group. However, the $T$. searsii- $T$. bicorne group was not always found.

\section{Comparison of the Sitopsis patterns to the Chinese Spring pattern}

The analysis was performed on the 11 lines or accessions, including $\mathrm{CS}$, i.e., taking into account 1231 spots. Three hundred and forty-six spots were found common to all the patterns and only 2 spots were found in every Sitopsis pattern but not in CS. Among the 750 spots of the CS pattern only 44 were not observed in the Sitopsis accessions.

Spots present only or absent only in one Sitopsis species and in CS were counted (table 2): these spots are very rare, but the $T$. speltoides-aucheri group is the one where the largest number of such spots was found.

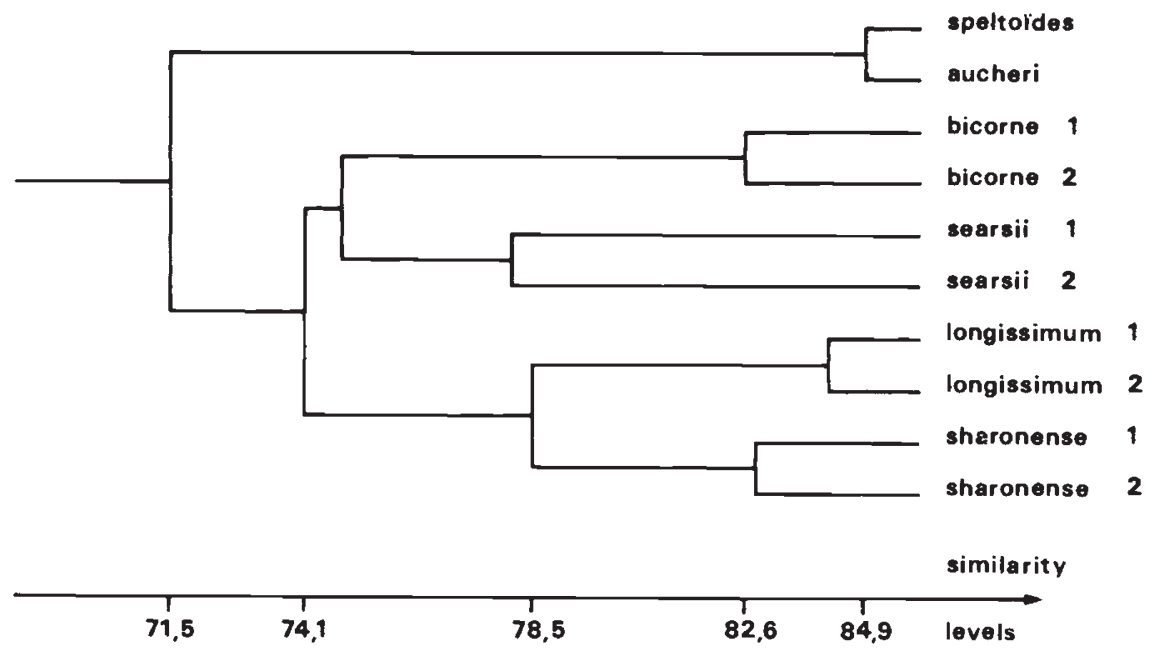

Figure 2 Dendrogram constructed from the similarity matrix of table 1, between the 10 Sitopsis accessions. 
Table 2 Number of spots present or absent in Chinese Spring and in only one Sitopsis accession or in only one Sitopsis species

\begin{tabular}{|c|c|c|c|}
\hline \multirow[b]{2}{*}{ And only in } & \multicolumn{3}{|c|}{ Number of spots } \\
\hline & Present in CS & Abse & t in CS \\
\hline $\begin{array}{l}\text { speltoides } \\
\text { aucheri } \\
\text { spelt }+ \text { auch }\end{array}$ & $\left.\begin{array}{c}1 \\
2 \\
11^{*}\end{array}\right\} 14^{*}$ & $\left.\begin{array}{l}0 \\
0 \\
6^{*}\end{array}\right\}$ & $6^{*}$ \\
\hline $\begin{array}{l}\text { bicorne } 1 \\
\text { bicorne } 2 \\
\text { bicorne } 1+2\end{array}$ & $\left.\begin{array}{l}0 \\
0 \\
2\end{array}\right\} \quad 2$ & $\left.\begin{array}{l}0 \\
0 \\
0\end{array}\right\}$ & 0 \\
\hline $\begin{array}{l}\text { longissimum } 1 \\
\text { longissimum } 2 \\
\text { longissimum } 1+2\end{array}$ & $\left.\begin{array}{l}1 \\
1 \\
1\end{array}\right\} \quad 3$ & $\left.\begin{array}{l}0 \\
0 \\
0\end{array}\right\}$ & 0 \\
\hline $\begin{array}{l}\text { searsii } 1 \\
\text { searsii } 2 \\
\text { searsii } 1+2\end{array}$ & $\left.\begin{array}{l}3 \\
2 \\
1\end{array}\right\} \quad 6$ & $\left.\begin{array}{l}1 \\
0 \\
0\end{array}\right\}$ & 1 \\
\hline $\begin{array}{l}\text { sharonense } 1 \\
\text { sharonense } 2 \\
\text { sharonense } 1+2\end{array}$ & $\left.\begin{array}{l}2 \\
2 \\
2\end{array}\right\} \quad 6$ & $\left.\begin{array}{l}0 \\
0 \\
0\end{array}\right\}$ & 0 \\
\hline
\end{tabular}

* Among them three are cytoplasmically encoded (see text).

A similarity matrix (table 3 ) and a dendrogram (fig. 3) were computed from the 11 by 1231 array. According to this method, the CS line was closer to the speltoides-aucheri group than to all the others Sitopsis. However it must be noted that the CS-searsii 1 similarity index was higher than the CS-speltoides or the CS-aucheri ones (78.1 versus $77 \cdot 4$ and $75 \cdot 5)$. But the CS-searsii 2 was among the lowest $(74 \cdot 1)$, which makes this group further from CS in the dendrogram. The similarity indices between CS and the Sitopsis (first column of table 3 ) were in fact very close to each others and most of them were not statistically different.

\section{DISCUSSION}

\section{Genetic relationships in the Sitopsis section}

The dendrogram presented in fig. 2 synthesises the information obtained on 1187 polypeptides. With the method of classification adopted, no a priori information was given on the intra-inter specific relations between the accessions. In all cases the two accessions of the same species were first grouped. $T$. speltoides and the $T$. aucheri were the two closest accessions. It seems very likely that they must be regrouped in the same species. This is in accordance with most of the Triticinae classifications that considered $T$. aucheri as a variety of $T$. speltoides, differing only by awn character, which may be linked with a reciprocal translocation (Zohary and Imber, 1963), although they were found to have different chloroplastic DNA restriction patterns (Tsunewaki and Ogihara, 1983).

The robustness of the classification was tested in the results section with no information on the intra- and interspecific structure of the comparisons. The fact that within species similarity indices were found greater than between species indices gives a great confidence to the results. However, for testing the robustness of the classification between species, the a priori information on species has also been used. A classification was done, taking into account only the spots that never varied within species (these spots can be considered as a sample of polypeptides less variable than others): 500 spots were selected according to this criterion (including the 348 non-variable spots). The dendrogram computed from them showed the same structure than the one presented in fig. 2, except there was no $T$. bicorne- $T$. searsii group.

A possible problem for the use of $2 \mathrm{D}$ electrophoresis for phylogenetic or taxonomic purposes

Table 3 Similarity matrix between the eleven accesions or lines

\begin{tabular}{|c|c|c|c|c|c|c|c|c|c|c|}
\hline spelt & $75 \cdot 5^{*}$ & & & & & & & & & \\
\hline auch & $77 \cdot 4^{*}$ & $85 \cdot 4$ & & & & & & & & \\
\hline bic 1 & $75 \cdot 5^{*}$ & $74 \cdot 2$ & $73 \cdot 2$ & & & & & & & \\
\hline bic 2 & $74 \cdot 2$ & $73 \cdot 1$ & $72 \cdot 6$ & $83 \cdot 3$ & & & & & & \\
\hline lon 1 & $73 \cdot 0$ & $72 \cdot 9$ & $75 \cdot 0$ & $76 \cdot 0$ & $75 \cdot 1$ & & & & & \\
\hline lon 2 & $74 \cdot 5$ & $72 \cdot 7$ & $73 \cdot 4$ & 76.8 & 76.0 & $84 \cdot 7$ & & & & \\
\hline sea 1 & $78 \cdot 1^{*}$ & $73 \cdot 7$ & $73 \cdot 5$ & $74 \cdot 5$ & $76 \cdot 0$ & $75 \cdot 0$ & $75 \cdot 8$ & & & \\
\hline sea 2 & $74 \cdot 1$ & $70 \cdot 2$ & $71 \cdot 2$ & $73 \cdot 8$ & $78 \cdot 7$ & $73 \cdot 1$ & $73 \cdot 8$ & $79 \cdot 0$ & & \\
\hline sha 1 & $76.0^{*}$ & $70 \cdot 8$ & $71 \cdot 6$ & $73 \cdot 8$ & $75 \cdot 3$ & 75.9 & $80 \cdot 1$ & $77 \cdot 5$ & $73 \cdot 0$ & \\
\hline sha 2 & $75 \cdot 9 *$ & $69 \cdot 9$ & $71 \cdot 5$ & $73 \cdot 4$ & $74 \cdot 0$ & $77 \cdot 5$ & $83 \cdot 3$ & $78 \cdot 1$ & $73 \cdot 8$ & $83 \cdot 4$ \\
\hline & CS & spelt & auch & bic 1 & bic 2 & lon 1 & lon 2 & sea 1 & sea 2 & sha 1 \\
\hline
\end{tabular}

* All those indices are not statistically different from the CS-sea 1 index. 


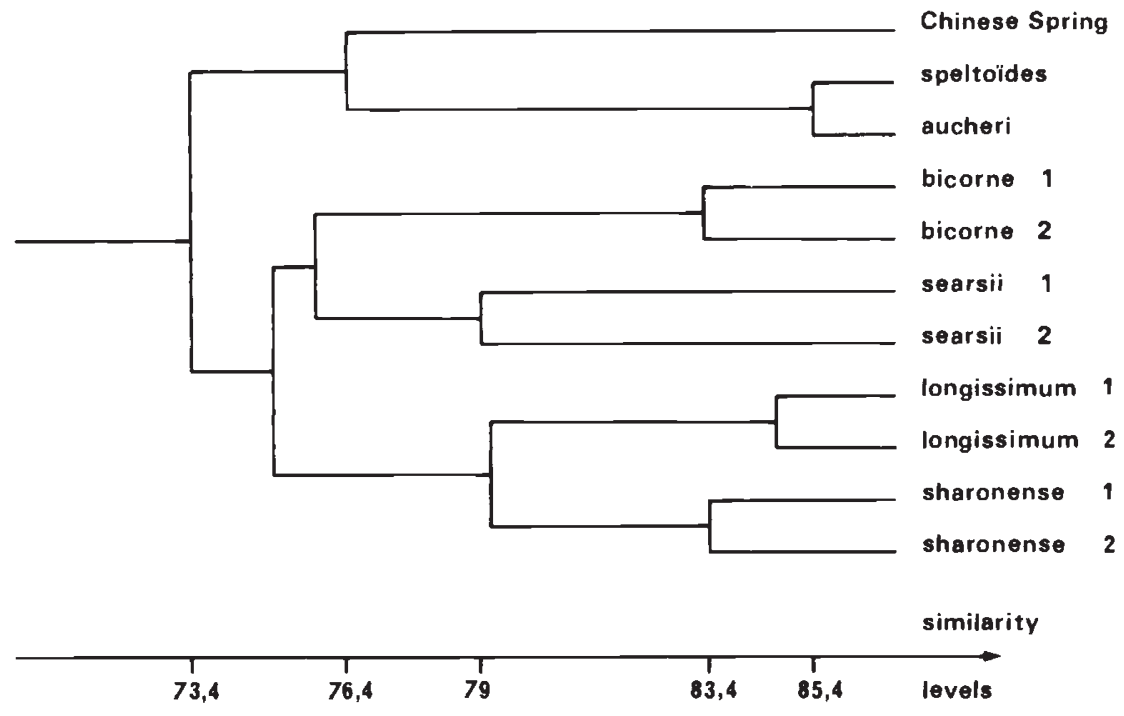

Figure 3 Dendrogram constructed from the similarity matrix of table 3, between the 11 accessions or lines (10 Sitopsis and CS).

is the existence of pleiotropic effects. Although only presence/absence variations were recorded, which are for most cases related to the allelic variation of structural genes, it can be argued that some of them could correspond to the variation of "regulators" that control the expression of those protein coding genes. In this case, the genetic variation of one regulator can lead to the similar variation of several spots, if several structural genes are under its control. The consequence of this phenomenon would be that groups of spots would have exactly the same behaviour according to the genotype, although they actually correspond to variation at only one gene. At worst, all spots showing a similar profile of presence/absence according to the ten accessions (i.e., identical lines in our array of data) could correspond to this phenomenon. Thus, the following spot selection was done: all the presence/absence profiles found among the 1187 Sitopsis spots were selected, but only one spot was retained when several had the same profile. Two hundred and ninety different profiles were scored. The classification according to this 10 by 290 array was very similar to the one shown in fig. 2. Thus, even if all spots showing a similar behaviour according to the ten accessions were due to pleiotropic effects (which is certainly not the case), the main structure of the classification remains.

Triticum sharonense and $T$. longissimum have been sometimes considered as conspecific, $T$. sharonense being a variety of $T$. longissimum (e.g., Kihara and Tanaka, cited by Lillenfeld, 1951). The observation that the speltoides-aucheri group is far apart from the rest of the Sitopsis species also confirms the concordance between our analysis and the common knowledge of the genetic proximities in the Sitopsis section. Thus, it appears that looking at hundreds of gene products by $2 \mathrm{D}$ electrophoresis produced valuable information, that supports several conclusions brought by other techniques. Although only two accessions per species were studied, a good structuration between intra- and inter-specific similarities was observed, except for $T$. searsii.

\section{Allelic variation within and between genomes}

Only 44 CS spots were not found in the Sitopsis accessions. Thus 94 per cent of the CS spots can be found in one or the other of these ten $S$ genome diploids. Since the CS pattern results from the expression of its three A, B and D genomes, it is very unlikely that all the more abundant proteins, i.e., the ones revealed by this $2 \mathrm{D}$ technique, were only the products of the $\mathrm{B}$ genome (the more related to $\mathrm{S}$ ). Moreover, we previously reported that 83 per cent of the CS spots can be found in one or the other of three representatives of the A genome (Seguin et al., 1987). We have also shown that up to 72 per cent of the CS spots can be found in one $T$. tauschii accession (D genome diploid) (Bahrman and Thiellement, 1987). Thus, since most spots of a hexaploid wheat can be found among the representatives of only one genome, it can be hypothesized that the same allelic forms 
are encountered at homologous (intragenomic) or homoeologous (intergenomic) structural gene loci.

This finding indicates that one must be very cautious about chromosomal assignment of a particular allele to one or the other wheat genome: an allelic form found on a given chromosome in a wheat variety can be found on a homoeologous chomosome in another variety.

\section{The origin of the $B$ genome of wheat}

The comparison of the CS pattern with those of the Sitopsis section addresses the problem of the comparison of diploid with hexaploid patterns. The CS pattern was expected to be far away from the Sitopsis ones, since polypeptides encoded by the $A$ and $D$ genomes will necessarily account for part of the CS pattern. However, it was also expected to be closer to the one among the Sitopsis accessions, that would be the most related to the $\mathrm{B}$ genome of the ABD hexaploid wheat. Admitting that the divergence between $\mathrm{A}, \mathrm{S}$, and $\mathrm{D}$ genomes began earlier than that within the $\mathrm{S}$ genome, there is no reason for one of the Sitopsis species to be more related to the A or D genomes, which would have induced a bias in the comparison.

The results of the analysis were that no accession was clearly closer to CS than the others. The closest accession was searsii 1 (similarity index: 78.1) (table 3), but the second accession of the species was among the farthest $(74 \cdot 1)$. The dendrogram of fig. 3 shows the $T$. speltoidesaucheri species as the closest to CS. This is because these two accessions have a good mean similarity to CS, although neither of them is the closest. The dendrogram computed with the "lowest similarity" criterion gave the same classification, but with the one computed with the "highest similarity" criterion, no species was more related to CS than the others. Nevertheless, it seems more logical to consider with more attention the mean similarity with one species.

When only the spots present or absent specifically in $\mathrm{CS}$ and in one other species are considered (table 2), it is with the speltoidesaucheri group that CS shares the highest number of such spots. Among the 14 spots present only in $\mathrm{CS}$ and in speltoides-aucheri, at least three are cytoplasmically encoded, the large subunit of Rubisco and two other proteins that are likely two forms of the beta subunit of the chloroplastic ATP synthase (Bahrman et al. 1988). Three other spots, specifically absent in CS and speltoides-aucheri, are the allelic forms of these same three chloroplastic gene products.
The data obtained on the cytoplasmically encoded proteins were non ambiguous: only $T$. speltoides and $T$. aucheri have the polyploid AABB, AAGG and AABBDD cytoplasmic type (Bahrman et al., 1988). The analysis reported here on more than a thousand gene products, whereas leading to the same conclusion, is less clear cut. Nevertheless, taking together the previous experiments (cytoplasmic type) and the present ones (dendrogram on all the spots and rare species specific allelic forms), it is the $T$. speltoides species (including $T$. aucheri) that is the closest to the ancient diploid form that gave the present $B$ genome of the cultivated wheats.

Acknowledgements We are grateful to Joël Blaisonneau, Martine Le Guilloux and Marie-Pierre Digard for expert technical assistance. We thank Dr Marianne Lefort-Buson and Dr François Rodolphe for their advice in statistics.

\section{REFERENCES}

Bahrman, N. AND thiellement, H. 1987. Parental genome expression in synthetic wheats (Triticum turgidum $\mathrm{sp} . \times T$. tauschii sp.) revealed by $2 \mathrm{D}$ electrophoresis of seedling proteins. Theor. Appl. Genet., 74, 218-223.

BAHRMAN, N., CARDIN, M.-L., SEGUIN, M., ZIVY, M. AND THIELLEMENT, H. 1988. Variability of 3 cytoplasmically encoded proteins in the Triticum genus. Heredity, 60, 87-90.

DAMERVAL, C., DE VIENNE, D., ZIVY, M. AND THIELLEMENT, H. 1986. Technical improvements in two-dimensional electrophoresis increase the level of genetic variations detected in wheat seedling proteins. Electrophoresis, 7, 52-54.

KERBY, K. AND KUSPIRA, J. 1987. The phylogeny of the polyploid wheats Triticum aestivum (bread wheat) and Triticum turgidum (macaroni wheat). Genome, 29, 722-737.

KLOSE, J. 1982. Genetic variability of soluble proteins studied by two-dimensional gel electrophoresis on different inbred mouse strains and on different organs. J. Mol. Evol., 18, 315-328.

LILLENFELD, F. A. 1951. H. Kihara: genome analysis in Triticum and Aegilops. X. Concluding review. Cytologia, $16,101-123$.

SEGUIN, M., ZIVY, M. AND THIELlEMENT, H. 1987. Comparison des diagrames bidimensionnels d'un Blé tendre (AABBDD) et de trois diploïdes de constitution génomique AA. "Lyonphorèse", Lyon, 12-14 novembre 1987.

THIELLEMENT, H. AND COLAS DES FRANCS, C. 1986. Similarity of two-dimensional protein patterns in a polyploid series of Triticum. Int. Symp. Plant Mol. Biol., Strasbourg, 8-11 July 1986, Abstract p. 61.

THIELLEMENT, H., ZIVY, M., COLAS DES FRANCS, C., BAHRMAN, N. AND GRANIER, F. 1987. Two-dimensional gel electrophoresis as a tool in wheat genetics. Biochimie, 69 , 781-787.

TSUNEWAKI, K. AND OGIHARA, Y. 1983. The molecular basis of genetic diversity among cytoplasms of Triticum and Aegilops species. II. On the origin of polyploid wheat cytoplasms as suggested by chloroplast DNA restriction fragment patterns. Genetics, 104, 155-171. 
ZIVY, M., THIELLEMENT, H., DE VIENNE, D. AND HOFMANN, J.-P. 1983. Study on nuclear and cytoplasmic genome expression in wheat by two-dimensional gel electrophoresis. 1. First results on 18 alloplasmic lines. Theor. Appl. Genet., 66, 1-7.
ZIVY, M., THIELLEMENT, H., DE VIENNE, D. AND HOFMANN, J.-P. 1984. Study on nuclear and cytoplasmic genome expression in wheat by two-dimensional gel electrophoresis. 2. Genetic differences between two lines and two groups of cytoplasms at five developmental stages or organs. Theor. Appl. Genet., 68, 335-345.

ZOHARY, D. AND IMBER, D. 1963. Genetic dimorphism in fruit types in Aegilops speltoides. Heredity, 18, 223-231. 